\title{
Reliability of catch per unit effort (CPUE) for evaluation of reintroduction programs - A comparison of the mark-recapture method with standardized trapping
}

\author{
J.K.M. Zimmerman ${ }^{(1)}$, R.T. Palo(1) \\ Received December 16, 2010 \\ Revised February 28, 2011 \\ Accepted March 7, 2011
}

\section{ABSTRACT}

Key-words: $\quad$ Catch per unit effort (CPUE) is used as a standardized trapping method Astacus astacus, by local fishermen and in monitoring studies. In this study, CPUE was CPUE, $\quad$ compared with population estimates made with a capture-recapture capture-recapture, method based on the passive integrated transponder (PIT-tag) marking reintroduction, of individuals.

evaluation

The results show a stronger positive correlation between the estimated population sizes from the capture-recapture method with an estimated CPUE effort of 120 traps. The fishermen used 15 traps, and even this effort showed a fair correlation with the mark-recapture estimates. This indicates that the standardized way of trapping with 15 traps can be used to evaluate reintroduction programs and monitor crayfish populations.

RÉSUMÉ

Fiabilité des captures par unité d'effort (CPUE) pour l'évaluation de programmes de réintroduction - une comparaison d'une méthode de capture-recapture avec du piégeage standardisé

Mots-clés : Les captures par unité d'effort (CPUE) sont utilisées comme méthode standardiAstacus astacus, sée de piégeage par les pêcheurs locaux et dans des études de suivi. Dans cette CPUE, étude, les CPUE sont comparées à des estimations de populations faites par mécapture-recapture, thode de capture-recapture avec marquage individuel par transpondeur intégré réintroduction, passif (PIT-tag).

évaluation

Les résultats montrent une forte corrélation positive entre les tailles estimées des populations par capture-recapture et les CPUE obtenues par 120 nasses. Les pêcheurs utilisent 15 nasses et pourtant leur effort montre une bonne corrélation avec les estimations par capture-recapture. Ceci indique que la méthode standardisée de piégeage par 15 nasses peut être employée pour évaluer le programme de réintroduction et réaliser le suivi de populations d'écrevisses.

\section{INTRODUCTION}

Reintroduction programs are conservation actions used in an attempt to reestablish species in areas where they have become extinct (IUCN, 1998; Seddon et al., 2007). The use of reintroductions has wide applications, but is often poorly documented or monitored for different

(1) Mid Sweden University, Department of Natural Sciences, Mathematics and Engineering, Holmgatan 10, 85170 Sundsvall, Sweden, Jenny.zimmerman@miun.se 
species (Fischer and Lindenmayer, 2000). There is a need for scientifically-based, accurate and cost-efficient methods to monitor and evaluate reintroduction programs. It is important that monitoring indicators are measurable, precise, consistent, and sensitive to the target (IUCN/SSC, 2008). The evaluation of different census methods is a necessary objective, since the establishment of populations in sites outside their normal range may be needed due to climate change. After a reintroduction, it is important to follow the performance of the species in question with monitoring and evaluation of population trends (IUCN, 1998). A cost-effective way to do this is to engage local people for trapping and monitoring. These locally-based surveys are defined as a broad set of simple monitoring techniques, often linked to local resource management programs and performed by amateurs (Danielsen et al., 2005). The involvement of local people has several advantages; it makes them committed to and educated in ecological management as well as more involved in conservation issues and projects. Rist et al. (2009) showed that locally-based monitoring was slightly less accurate than scientific methods, but much more cost-efficient and sustainable long-term.

Rather than analyzing and reporting data as actual numbers, a catch per unit effort (CPUE) is commonly used. CPUE standardizes the data based on the effort, i.e. the number of individuals caught per number of traps and total time of the trapping event. CPUE assumes constant catchability and that all animals have the same probability of being captured (Schwarz and Seber, 1999). Given these assumptions, CPUE can be used as an abundance index (Schaefer, 1954; Harley et al., 2001; Hinton and Maunder, 2003; Laloë, 2007). It is also assumed that CPUE is proportional to the abundance at the time of collection and that the proportion of the trappable cohort of the population is constant over time. This is often not true in free-living populations. CPUE is affected by many variables, including fishing techniques (Goodyear et al., 2003; Maunder et al., 2006), behavior of the fishermen (Laloë, 2007), and factors affecting the organism, such as water temperature, substrate size and presence of predators (Abrahamsson, 1983; Somers and Stechey, 1986; Dorn et al., 2005). It is also possible that for populations at different localities, CPUE may not be synchronized, even if they are under the same harvest policy (Maunder et al., 2006). Because sampling efforts may differ from area to area, month to month, or year to year, the number of crayfish captured must be analyzed in such a way as to standardize the effort that was exerted.

A stable CPUE may reflect exploitation at Maximum Sustainable Yield (MSY) as well as the possible change of a fishing method to compensate for fishing due to decreasing abundance (Jones, 2004). CPUE has been used as a proxy for population estimations of crayfish (Skurdal et al., 2002; Westman et al., 2002; Olsson et al., 2010; Zimmerman and Palo, 2010) and for the evaluation of stocking success in Finnish waters (Erkamo et al., 2010).

Capture-recapture methods have been used for crayfish monitoring (Skurdal et al., 1992; Westman and Savolainen, 2001; Maguire et al., 2004; Nowicki et al., 2008) and a probabilistic time-to-event model has been used to determine and evaluate the success of crayfish introductions (Sahlin et al., 2010). The latter methods are more complex, expensive and timedemanding than CPUE estimation, and also require more advanced data handling.

In this study, we investigate the reliability of CPUE estimated from a standardized trapping method conducted by local fishermen compared with population estimations made with the capture-recapture method. We ask if a simplified capture protocol with CPUE is satisfactory to evaluate the success or failure of a reintroduction program.

\section{MATERIALS AND METHODS}

\section{$>$ STUDY AREA}

The noble crayfish (Astacus astacus) populations in the Swedish river Ljungan (latitude $62^{\circ} \mathrm{N}$ ) became extinct in 1999. The river was formerly known as one of the most valuable and productive noble crayfish sites in Sweden (Odelström and Johansson, 1999). A reintroduction program was launched by the local, regional and national authorities in cooperation with local fishermen in 2002. To date, more than 80000 crayfish have been reintroduced at 35 sites 
along the river. The crayfish were taken from a lake in the nearby region. Recruitment to the cohort that could be trapped comes from two sources - the restocking of crayfish in late September each year, and after moulting during the summer when a new size class enters into the cohort that is trappable. The goal of the reintroduction program is not only to create a viable population of crayfish in its former waters, but also to increase the population size to a level where it is possible to locally harvest crayfish. Commercial or household fishing is banned until the crayfish stock is large enough to sustain harvest. To evaluate the success of the reintroduction program, the local fishermen have been trapping crayfish in a standardized way since 2004 at 35 sites. Five of the sites (Viken, Ovansjö, Näset, Västanå and Ljunga) were chosen for comparisons of CPUE and capture-recapture studies. The sites are approximately $50 \mathrm{~km}$ apart from west to east. Viken is the most upstream site and Ljunga the most downstream.

The trapping performance and the trapping protocol were modified from the Swedish standard method of crayfish monitoring (Bergqvist et al., 2005). Five baited traps, cylindrical LiNi Traps with two entrances and 14-mm mesh size, were arranged on a separate line and positioned across the river bed. The distance between the traps was $10 \mathrm{~m}$, e.g. within the radius where bait attracts crayfish in the vicinity (Acosta and Perry, 2000; Cukerzis, 1989 and Fedotov, 1993 cited by Kholodkevich et al., 2005).

The fishermen's protocol used three lines, in total 15 traps $\left(\mathrm{CPUE}_{15}\right)$, which were positioned at the reintroduction site, $100 \mathrm{~m}$ downstream and $100 \mathrm{~m}$ upstream of the reintroduction site. The traps were baited with roach or perch, except in 2010, when Trappy (Smålandsmjärden AB, Virserum, Sweden) crayfish bait inside a bait box was used. Trapping was performed by the local fishermen in late August and data were collected using a protocol that noted the number of crayfish per trap. After trapping, the crayfish were released into the river at the same spot as for capture.

Our trapping was performed approximately two weeks after the fishermen's, and conducted at the same sites. We used 24 lines; in total 120 traps $\left(\mathrm{CPUE}_{120}\right)$. These were positioned at a stretch of $100 \mathrm{~m}$ on both sides of the river bank downstream of the reintroduction site. The sampling procedure was the same as the fishermen's protocol.

In total, 700 crayfish at each site were caught and marked individually with Passive Integrated Transponders PIT-tags (Trovan ID 100 A) (Bubb et al., 2002) during the second weeks of June, August and September from 2007 to 2010. In August 2010, additional crayfish to those marked with PIT-tags were marked with Tipp-Ex and included in the recapture record in September 2010.

\section{> DATA ANALYSIS}

Data were analyzed using the program $R$, version 2.9.0. Population estimations were made with the package Rcapture (Baillargeon and Rivest, 2007). Trapping data in terms of CPUE 15 and $\mathrm{CPUE}_{120}$ were not normally distributed and for this reason, the Mann Whitney U-test was used to compare differences in $\mathrm{CPUE}_{15}$ and $\mathrm{CPUE}_{120}$. To detect a possible effect due to the change of the fishermen's bait, the quotients of standard deviation and mean of the yearly CPUE $_{15}$ were calculated and the quotients were analyzed with Student's $t$-test.

The estimation of the population size was done with capture-recapture techniques according to the robust design described by Pollock (1982). This allowed us to pool the recapture data from August and September each year into a primary period, under the assumption of closed populations, and these were analyzed with log linear closed population models (Seber, 1986; Nichols, 1992). In the models, $M_{0}$, assumes that all individuals have the same probability of being captured at every trapping occasion, irrespective of which one, $M_{t}$ assumes that all population members have the same risk of being captured at the same trapping occasion, but the probability of catch is different between sampling occasions, and $M_{h}$ assumes that all individuals have their own independent probability of capture compared with the other members, irrespective of which trapping occasion (Otis et al., 1978). The best model was selected with the Akaike's information criterion (AIC) and the standard errors of the models. 


\section{Table I}

CPUE for different efforts; 15 and 120 traps, respectively. The yearly results are presented as mean and standard deviations.

Tableau I

CPUE pour des efforts de 15 et 120 nasses. Les moyennes et déviations standard sont présentées par année.

\begin{tabular}{|c|cc|cc|}
\hline \multirow{2}{*}{ Year } & \multicolumn{2}{|c|}{ CPUE $_{15}$} & \multicolumn{2}{c|}{ CPUE $_{120}$} \\
\cline { 2 - 5 } & Mean & Sd & Mean & Sd \\
\hline $\mathbf{2 0 0 7}$ & 2.0 & 0.7 & 0.8 & 0.5 \\
\hline $\mathbf{2 0 0 8}$ & 2.6 & 1.6 & 1.5 & 0.5 \\
\hline $\mathbf{2 0 0 9}$ & 3.0 & 1.4 & 1.2 & 0.7 \\
\hline $\mathbf{2 0 1 0}$ & 4.5 & 1.7 & 2.4 & 0.9 \\
\hline
\end{tabular}

Additionally, the model chosen was assumed to be universally applicable to all the sampling occasions. The relationships of the log-transformed CPUE and the abundance estimations were tested with the Pearson correlation test and linear regression.

\section{RESULTS}

CPUE $_{15}$ was larger than CPUE $_{120}$ and this was also true for the variation in trapping data. The median for $\mathrm{CPUE}_{15}$ was 2.7, ranging from 0.9 to 6.9, whereas the value for $\mathrm{CPUE}_{120}$ was 1.4, ranging from 0.4 to 3.6. The difference was significant (Mann Whitney U-test, $p<10^{-3}$ ). CPUE $_{15}$ and CPUE $_{120}$ showed increasing trends during the studied period (Table I). The quotients of standard deviation and the mean of yearly $\mathrm{CPUE}_{15}$ did not differ significantly from the expected distribution (Student's $t$-test, $p$-value $=0.008$ ), indicating no effect of the changed bait in 2010 for the fishermen.

The closed population model, the $\mathrm{M}_{\mathrm{t}}$-model, was best fitted to the recapture data. At all localities the abundances increased overall during the studied period and the standard errors of the abundance estimations showed a decreasing trend (Table II).

The log-transformed $\mathrm{CPUE}_{15}$ and $\mathrm{CPUE}_{120}$ were both positively correlated with the abundance estimated from the recapture data (Figure 1). However, the strength in correlation differed and the $\mathrm{CPUE}_{15}$ (Pearson correlation $=0.48, p=0.03$ ) was fair, but the $\mathrm{CPUE}_{120}$ (Pearson correlation $=0.68, p=0.001$ ) was moderately strong according to the classification by Chan (2003). The linear regressions with $\mathrm{CPUE}_{15}$ and $\mathrm{CPUE}_{120}$ versus abundance based on capture-recapture were significant, but the explanatory power was not high. The correlation coefficient was higher for $\mathrm{CPUE}_{120}\left(\log \left(\mathrm{CPUE}_{120}\right)=0.75^{\star} \log (\right.$ abundance $\left.)-4.54, \mathrm{R}^{2}=0.46\right)$ than for $\mathrm{CPUE}_{15}\left(\log \left(\mathrm{CPUE}_{15}\right)=0.46^{\star} \log (\right.$ abundance $\left.)-1.96, \mathrm{R}^{2}=0.23\right)$.

\section{DISCUSSION}

A positive correlation was found between CPUE and population estimations made with capture-recapture methods for noble crayfish. The correlation was stronger with an effort of 120 traps than the 15 traps used by fishermen. This is consistent with data from Westman et al. (2002), who found a relationship between CPUE and capture-recapture methods for both noble and signal crayfish. However, Hockley et al. (2005) found low statistical power when using local people for monitoring and pointed out that CPUE might be considered suitable for monitoring only if properly standardized.

Bubb et al. (2002) showed that the method of marking crayfish with pit-tags gave $100 \%$ tag retention after one moult, without affecting survival. About $40 \%$ of the marked animals in this study were recaptured at least once. This concurs with previous results that reported recapture ranging from 15 to 50\% (Abrahamsson, 1966; Westman et al., 2002; Maguire et al., 2004; Scalici et al., 2008). 


\section{Table II}

CPUE and population abundance estimations at the study sites. The results are presented as CPUE for different efforts, estimated population size (abundance) and standard error of the population size.

Tableau II

CPUE et estimations d'abondance dans les sites de l'étude. Les CPUE pour différents efforts, la taille estimée des populations (abondance) et l'erreur standard de cette taille sont présentées.

\begin{tabular}{|c|c|c|c|c|c|}
\hline Year & Site & CPUE $_{15}$ & CPUE $_{120}$ & Abundance & S.E. \\
\hline $\mathbf{2 0 0 7}$ & Viken & 2.7 & 0.6 & 289.3 & 69.4 \\
\hline $\mathbf{2 0 0 7}$ & Ovansjö & 1.9 & 1.8 & 697.2 & 77 \\
\hline $\mathbf{2 0 0 7}$ & Näset & 2.6 & 0.8 & 410.7 & 69.3 \\
\hline $\mathbf{2 0 0 7}$ & Västanå & 0.9 & 0.4 & 181.6 & 41 \\
\hline $\mathbf{2 0 0 7}$ & Ljunga & 1.8 & 0.6 & 293.2 & 70.4 \\
\hline $\mathbf{2 0 0 8}$ & Viken & 5.3 & 1.3 & 525.5 & 59.1 \\
\hline $\mathbf{2 0 0 8}$ & Ovansjö & 2.5 & 2.1 & 1004.3 & 127.8 \\
\hline $\mathbf{2 0 0 8}$ & Näset & 1.9 & 1.4 & 551.1 & 94.2 \\
\hline $\mathbf{2 0 0 8}$ & Västanå & 1.2 & 0.9 & 343.2 & 62.2 \\
\hline $\mathbf{2 0 0 8}$ & Ljunga & 2.2 & 1.6 & 869.9 & 126.2 \\
\hline $\mathbf{2 0 0 9}$ & Viken & 1.7 & 0.7 & 1169 & 288.3 \\
\hline $\mathbf{2 0 0 9}$ & Ovansjö & 3.1 & 2.2 & 1455.1 & 250.9 \\
\hline $\mathbf{2 0 0 9}$ & Näset & 5.1 & 0.5 & 702.1 & 193.6 \\
\hline $\mathbf{2 0 0 9}$ & Västanå & 1.8 & 1.3 & 422.5 & 51.9 \\
\hline $\mathbf{2 0 0 9}$ & Ljunga & 3.0 & 1.5 & 532.3 & 60.3 \\
\hline $\mathbf{2 0 1 0}$ & Viken & 3.0 & 1.6 & 1169 & 288.3 \\
\hline $\mathbf{2 0 1 0}$ & Ovansjö & 3.0 & 3.6 & 1376.8 & 80.1 \\
\hline $\mathbf{2 0 1 0}$ & Näset & 6.9 & 1.5 & 914.9 & 122.2 \\
\hline $\mathbf{2 0 1 0}$ & Västanå & 4.3 & 2.6 & 613.6 & 43.4 \\
\hline $\mathbf{2 0 1 0}$ & Ljunga & 5.6 & 2.9 & 841.6 & 64.1 \\
\hline
\end{tabular}

Several capture-recapture studies have been conducted in August and September in Scandinavia, when trappability and the activity of both sexes are equal (Abrahamsson, 1966; Westman and Pursianen, 1982; Skurdal et al., 1992). Closed populations between sampling occasions in August and September were assumed in this study, implying no recruitment, mortality, immigration or emigration during this period (Pollock et al., 1990). This is obviously not the case in most situations, but it is possible to estimate the abundance without bias if natural mortality acts equally upon marked and unmarked animals (White et al., 1982). In this study, the time period of one month between August and September was assumed not to significantly alter the demography of the population (Momot, 1967; Brewis and Bowler, 1983; Gydemo, 1989; Skurdal and Taugbøl, 2002; Nowicki et al., 2008).

Some sites showed large standard errors of the population estimations, which may be overestimated (Table II). In cases with large variations in the data, the temporal model gives uncertain predictions. However, the standard errors of the estimates in the study seem to gradually decrease. As the accumulated number of marked individuals increases in the water, the abundance estimation is more accurate.

The number of traps is obviously important for reliable estimates of abundance and population trends. Our results show that a possible saturation effect occurs with a larger number of traps. This effect may explain the difference between the $\mathrm{CPUE}_{15}$ and $\mathrm{CPUE}_{120}$ trap protocols with lower values of $\mathrm{CPUE}_{120}$. In addition, a larger number of traps covers a larger area, leading to the possibility that habitat variation plays a role in the number of catches. Catching with traps is biased towards large crayfish, and excludes smaller individuals (Dorn et al., 2005; Price and Welch, 2009), especially females (Abrahamsson, 1966; Rabeni et al., 1997). The size of the actual population is probably underestimated and the recruitment of size classes not trapped is hard to predict (Dorn et al., 2005). More reliable population estimates can be obtained if the survey is carried out when both sexes are active (Westman and Pursiainen, 1982). Therefore, the timing and trapping season are important for a qualitative estimation of CPUE. 
Figure 1A

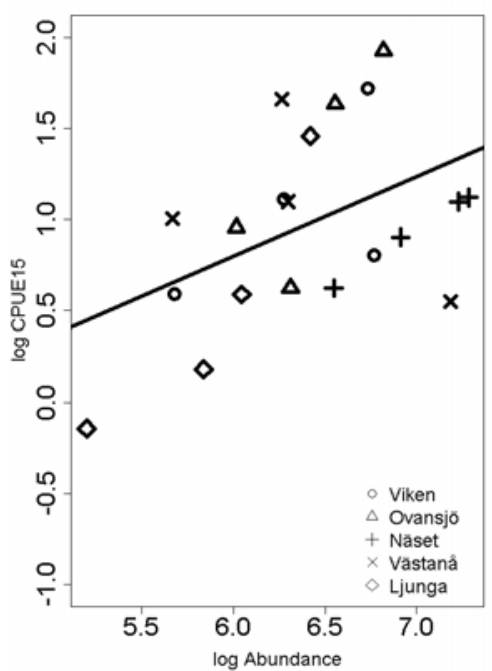

Figure 1B

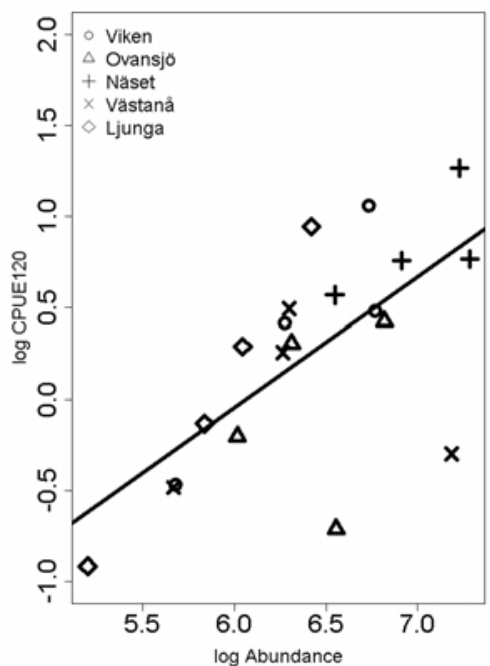

Figure 1

Relationships between crayfish abundance and CPUE for different trap efforts at the study sites Viken (o), Ovansjö $(\Delta)$, Näset $(+)$, Västanå $(x)$ and Ljunga $(\diamond)$. Figure $1 A$ presents $\log \left(\mathrm{CPUE}_{15}\right)=0.46 * \log ($ abundance $)$ $\left.-1.96, R^{2}=0.23\right)$ and Figure $1 B \log \left(\mathrm{CPUE}_{120}\right)=0.75^{*} \log ($ abundance $)-4.54, R^{2}=0.46$.

Figure 1

Relation entre l'abondance des écrevisses et les CPUE avec différents efforts de piégeage aux sites d'étude Viken (o), Ovansjö $(\Delta)$, Näset $(+)$, Västanå $(\times)$ et Ljunga $(\diamond)$. Régressions $1 \mathrm{~A}: \log \left(\mathrm{CPUE}_{15}\right)=$ $0,46^{\star} \log ($ abondance $)-1,96 ; R^{2}=0,23$ et $1 B: \log \left(C^{\prime} U_{120}\right)=0,75^{\star} \log ($ abondance $)-4,54 ; R^{2}=0,46$.

\section{CONCLUSION}

Despite the limitations caused by trapping equipment, CPUE and the standardized trapping method can be used as an index for population trends. Caution should be taken when interpreting the actual population size due to bias in the size distribution of captured individuals (Kirjavainen and Westman, 1999). Still, CPUE is valuable for the evaluation of restocking and reintroduction programs. A major result from this study is that more effort, i.e. more traps, gives better accuracy in relation to mark-recapture techniques.

The design used by fishermen, with 15 traps, seems to be a less accurate, but reasonable method when the cost of monitoring needs to be low.

Our conclusion from this study is that the reintroduction program to the river Ljungan is to date a success. After eight years of reintroduction, all the populations studied seem to have developed and increased. Different localities have different rates of increase and the reason for this variation needs to be further investigated.

\section{ACKNOWLEDGEMENTS}

This work was done in cooperation with the LEADER projects "Förstudie för Älvens Hus" and "Återintroduktion av flodkräfta till Ljungan". We would like to thank all the field assistants, all the fishery rights owners' associations for data and support, Ånge municipality for financial support, Permascand AB, Ånge Judoklubb and Karlsro Flyers for housing of the field assistants, Wayne Chan for correcting the language, and Lennart Edsman at the Swedish Board of Fisheries Institute of Freshwater Research. 


\section{REFERENCES}

Abrahamsson S.A.A., 1966. Dynamics of an isolated population of the crayfish Astacus astacus Linné. Oikos, 17, 96-107.

Abrahamsson S.A.A., 1971. Fecundity and growth of some populations of Astacus astacus Linné in Sweden. Rep. Inst. Freshw. Res. Drottningholm, 52, 23-27.

Abrahamsson S.A.A., 1983. Trappability, locomotion and diel pattern of activity of the crayfish Astacus astacus and Pacifastacus leniusculus Dana. Freshw. Crayfish, 5, 239-253.

Acosta C.A. and Perry S.A., 2000. Effective sampling area: A quantitative method for sampling crayfish populations in freshwater marshes. Crustaceana, 73, 425-431.

Baillargeon S. and Rivest L., 2007. Rcapture: Loglinear models for capture-recapture in R. J. Stat. Soft., 19, 1-31.

Bergqvist B., Bohman P. and Edsman L., 2005. Provfiske efter kräfta i sjöar och vattendrag. http://www. naturvardsverket.se/upload/02_tillstandet_i_miljon/Miljoovervakning/undersokn_typ/sotvatten/ kraftprov.pdf. Downloaded on 31 January 2011 (in Swedish).

Brewis J.M. and Bowler K., 1983. A study of the natural population of the freshwater crayfish, Austropotamobius pallipes. Freshw. Biol., 13, 443-452.

Bubb D.H., Lucas M.C., Thom T.J. and Rycroft P., 2002. The potential use of PIT telemetry for identifying and tracking crayfish in their natural environment. Hydrobiologia, 483, 225-230.

Chan Y.H., 2003. Biostatistics 104: Correlational Analysis. Singapore Med. Journal, 44, 614-619.

Danielsen F., Burgess N.D. and Balmford A., 2005. Monitoring matters: examining the potential of locallybased approaches. Biodiversity Conserv., 14, 2507-2542.

Dorn N.J., Urgelles R. and Trexler J.C., 2005. Evaluating active and passive sampling methods to quantify crayfish density in a freshwater wetland. J. N. Am. Benthol. Soc., 24, 346-356.

Erkamo E., Ruokonen T., Alapassi T., Ruokolainen J., Järvenpää T., Tulonen J. and Kirjavainen J., 2010. Evaluation of crayfish stocking success in Finland. Freshw. Crayfish, 17, 77-83.

Fischer J. and Lindenmayer D.B., 2000. An assessment of the published results of animal relocations. Biol. Conserv., 96, 1-11.

Goodyear C.P., Die D., Kerstetter D.W., Olson D.B., Prince E. and Scott G.P., 2003. Habitat standardization of CPUE indices: research needs. Col. Vol. Sci. Pap. ICCAT, 55, 613-623.

Gydemo R., 1989. Reproduction and Growth in the Noble Crayfish Astacus astacus L., Ph.D. thesis, University of Stockholm, Stockholm.

Harley S.J., Myers R.A. and Dunn A., 2001. Is catch-per-unit-effort proportional to abundance? Can. J. Fish. Aquat. Sci., 58, 1760-1772.

Hinton M.G. and Maunder M.N., 2003. Methods for standardizing CPUE and how to select among them. Col. Vol. Sci. Pap. ICCAT, 56, 169-177.

Hockley N.J., Jones J.P.G., Andriahajaina F.B., Manica A., Ranambitsoa E.H. and Randriamboahary J.A., 2005. When should communities and conservationists monitor exploited resources? Biodivers. Cons., 14, 2795-2806.

IUCN (World Conservation Union), 1998. Guidelines for reintroductions, Gland and Cambridge.

IUCN/SSC (IUCN Species Survival Commission), 2008. Strategic Planning for Species Conservation: A Handbook, Version 1.0, Gland, $71 \mathrm{p}$.

Jones J.P.G., 2004. The sustainability of crayfish harvesting in Ranomafana National Park, Madagascar, Ph.D. thesis, University of Cambridge, Cambridge, $161 \mathrm{p}$.

Kholodkevich S., Shumilova T., Fedotov V. and Zhuravlev D., 2005. Effects of the Astacus astacus L. population on biomass of macrophytes in a fresh water body. Russ. J. Ecol., 36, 271-276.

Kirjavainen J. and Westman K., 1999. Natural history and development of the introduced signal crayfish, Pacifastacus leniusculus, in a small, isolated Finnish lake, from 1968 to 1993. Aquat. Living Resour., 12, 387-401.

Laloë F., 2007. Modelling sustainability: from applied to involved modeling. Soc. Sci. Inform., 46, 87-107.

Maguire I., Hudina S. and Erben R., 2004. Estimation of noble crayfish (Astacus astacus L.) population size in the Velika Paklenica stream (Croatia). Bull. Fr. Pêche Piscic., 372-373, 353-366.

Maunder M.N., Sibert J.R., Fonteneau A., Hampton J., Kleiber P. and Harley S.J., 2006. Interpreting catch per unit effort data to assess the status of individual stocks and communities. ICES J. Mar. Sci., 63, 1373-1385. 
Momot W.T., 1967. Population dynamics and productivity of the crayfish, Orconectes virilis, in a marl lake. Am. Mid. Nat., 78, 55-81.

Nichols J.D., 1992. Capture-recapture models. BioScience, 42, 94-102.

Nowicki P., Tirelli T., Mussat Sartor R., Bona F. and Pessani D., 2008. Monitoring crayfish using a mark-recapture method: potentials, recommendations, and limitations. Biodivers. Conserv., 17, 3513-3530.

Odelström T. and Johansson S., 1999. Flodkräftodling i Norrland - biologiska och ekonomiska förutsättningar. In: Fiskeriverket rapport 1999:1, Stockholm, 17 p. (in Swedish).

Olsson K., Granéli W., Ripa J. and Nyström P., 2010. Fluctuations in harvest of native and introduced crayfish are driven by temperature and population density in previous years. Can. J. Fish. Aquat. Sci., 67, 157-164.

Otis D.L., Burnham K.P., White G.C. and Anderson D.R., 1978. Statistical inference from capture data on closed animal populations. Wildlife Monogr., 62,135 p.

Pollock K.H., 1982. A capture-recapture design robust to unequal probability of capture. J. Wildlife Manage., 46, 752-757.

Pollock K.H., Nichols J.D., Brownie C. and Hines J.E., 1990. Statistical inference for capture-recapture experiments. Wildlife Monogr., 107, 3-97.

Price J.E. and Welch S.M., 2009. Semi-quantitative methods for crayfish sampling: Sex, size, habitat bias. J. Crustacean Biol., 29, 208-216.

Rabeni C.F., Collier F.J., Parkyn S.M. and Hicks B.J., 1997. Evaluating techniques for sampling stream crayfish (Paranephrops planifrons). New Zeal. J. Mar. Fresh., 31, 693-700.

Rist J., Milner-Gulland E.J., Cowlishaw G. and Rowcliffe M., 2009. Hunter reporting of catch per unit effort as a monitoring tool in a bushmeat-harvesting system. Conserv. Biol., 24, 489-499.

Sahlin U., Smith H.G., Edsman L. and Bengtsson G., 2010. Time to establishment success for introduced signal crayfish in Sweden - a statistical evaluation when success is partially known. J. Appl. Ecol., 47, 1044-1052.

Scalici M., Belluscio A. and Gibertini G., 2008. Understanding population structure and dynamics in threatened crayfish. J. Zool., 275, 160-171.

Schaefer M.B., 1954. Some aspects of the dynamics of populations important to the management of commercial marine fisheries. Bull. Inter-Am. Tropical Tuna Comm., 1, 25-56.

Schwarz C.J. and Seber G.A.F., 1999. Estimating animal abundance. Review III. Stat. Sci., 14, 427-456.

Seber G.A.F., 1986. A review of estimating animal abundances. Biometrics, 42, 267-292.

Seddon P.J., Armstrong D.P. and Maloney R.F., 2007. Developing the science of reintroduction biology. Conserv. Biol., 21, 303-312.

Skurdal J. and Taugbøl T., 2002. Astacus. In: Holdich D.M. (ed.), Biology of freshwater crayfish, Blackwell Science Ltd, Oxford, 467-510.

Skurdal J., Qvenild T. and Taugbøl T., 1992. Mark-recapture experiments with noble crayfish, Astacus astacus L., in a Norwegian lake. Aquac. Res., 23, 227-223.

Skurdal J., Garnås E. and Taugbøl T., 2002. Management strategies, yield and population development of the noble crayfish Astacus astacus in lake steinsfjorden. Bull. Fr. Pêche Piscic., 367, 845-860.

Somers K. and Stechey D.P.M., 1986. Variable trappability of crayfish associated with bait type, water temperature and lunar phase. Am. Mid. Nat., 116, 36-44.

Westman K. and Pursiainen M., 1982. Size and structure of crayfish (Astacus astacus) populations on different habitats in Finland. Hydrobiologia, 86, 67-72.

Westman K. and Savolainen R., 2001. Long term study of competition between two co-occurring crayfish species, the native Astacus astacus L. and the introduced Pacifastacus leniusculus Dana, in a Finnish lake. Bull. Fr. Pêche Piscic., 361, 613-627.

Westman K., Savolainen R. and Julkunen M., 2002. Replacement of the native crayfish Astacus astacus by the introduced species Pacifastacus leniusculus in a small, enclosed Finnish lake: a 30-year study. Ecography, 25, 53-73.

White G.C., Anderson D.R., Burnham K.P. and Otis D.L., 1982. Chapter 1: Introduction. In: Capturerecapture and removal methods for sampling closed populations, Los Alamos National Laboratory, Park Ridge, $4 \mathrm{p}$.

Zimmerman J.K.M. and Palo R.T., 2010. Influence of water regulation and water flow on noble crayfish (Astacus astacus) catch yield in the river Ljungan. Freshw. Crayfish, 17, 141-144. 